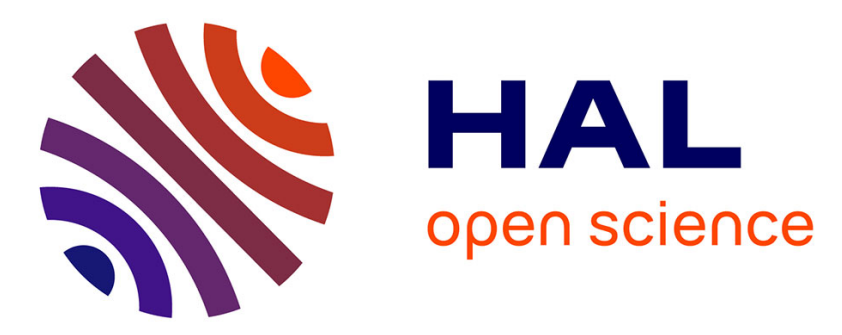

\title{
Patterns of bird song evolution on islands support the character release hypothesis in tropical but not in temperate latitudes
}

Aloïs Robert, Martim Melo, Thierry Lengagne, Sacha Julien, Doris Gomez, Claire Doutrelant

\section{To cite this version:}

Aloïs Robert, Martim Melo, Thierry Lengagne, Sacha Julien, Doris Gomez, et al.. Patterns of bird song evolution on islands support the character release hypothesis in tropical but not in temperate latitudes. Journal of Evolutionary Biology, 2021, 34 (10), pp.1580-1591. 10.1111/jeb.13928 . hal03373546

\author{
HAL Id: hal-03373546 \\ https://hal.science/hal-03373546
}

Submitted on 19 Oct 2021

HAL is a multi-disciplinary open access archive for the deposit and dissemination of scientific research documents, whether they are published or not. The documents may come from teaching and research institutions in France or abroad, or from public or private research centers.
L'archive ouverte pluridisciplinaire HAL, est destinée au dépôt et à la diffusion de documents scientifiques de niveau recherche, publiés ou non, émanant des établissements d'enseignement et de recherche français ou étrangers, des laboratoires publics ou privés. 
1 Tittle: Patterns of bird song evolution on islands support the character release hypothesis in

2 tropical but not in temperate latitudes

3 Short tittle: Island birds use broad song frequency range

4 Aloïs Robert ${ }^{1 \dagger}$, Martim Melo ${ }^{2-4}$, Thierry Lengagne ${ }^{5}$, Sacha Julien ${ }^{1}$, Doris Gomez ${ }^{1}$, Claire Doutrelant ${ }^{1}$

$5 \quad{ }^{1}$ CEFE UMR 5175, CNRS - Univ. Montpellier - EPHE, 1919 route de Mende, 34293 Montpellier,

6 Cedex 05 France

$7{ }^{2}$ CIBIO Centro de Investigação em Biodiversidade e Recursos Genéticos, InBio Laboratório

8 Associado, Campus Agrário de Vairão, Universidade do Porto, 4485-661 Vairão, Portugal

$9{ }^{3}$ MHNC-UP Museu de História Natural e da Ciência da Universidade do Porto, Praça Gomes 10 Teixeira 4099-002 Porto, Portugal

$11{ }^{4}$ FitzPatrick Institute of African Ornithology, DST Centre of Excellence, University of Cape Town, 127701 Rondebosch, South Afric

$135{ }^{5}$ UMR 5023 Université de Lyon, Écologie des Hydrosystèmes Naturels et Anthropisés, Université 14 Lyon 1, ENTPE, CNRS, Villeurbanne, France

15 Corresponding author: Aloïs ROBERT

16 CEFE UMR 5175, CNRS

$17 \quad 1919$ Route de Mende

$18 \quad 34090$ Montpellier

19 FRANCE 


\section{ORCID:}

22 Aloïs ROBERT:0000-0003-2890-7547

23 Martim Melo: 0000-0003-1394-4361

24 Thierry Lengagne: 0000-0001-7840-6068

25 Sacha Julien: not available

26 Doris Gomez: 0000-0002-9144-3426

27 Claire Doutrelant: 0000-0003-1893-3960

\section{Declaration of interest}

30 The authors have no conflict of interest to declare.

\section{Acknowledgments}

33 We are extremely thankful to everyone who made this study possible. Francis Njie provided invaluable

34 assistance in Cameroon, Octávio Veiga on São Tomé, and Malicia Besnard in France. Facundo 35 Fernandez-Duque helped in data analysis. We also thank Rita Covas, Clémentine Vignal, Jérôme Sueur 36 and two anonymous reviewers for their constructive comments. Thierry Aubin and Fanny Rybak 37 provided the SM3 and we thank them for the discussions we had.

39 funded by the University of Montpellier; MM was supported via the European Union's Horizon 2020

40 research and innovation programme under grant agreement No 854248; CD, TL \& DG by the CNRS.

41 This research was conducted under the scope of the International Associated Laboratory (LIA)

42 'Biodiversity and Evolution' between the CNRS (France) and CIBIO (Portugal). Fundação para a

43 Ciência e a Tecnologia (Portugal) provided structural funding to CIBIO (UIDB/50027/2021). 


\section{Author contributions}

46 C.D., M.M, D.G., T.L. and A.R. designed this study. C.D., M.M, S.J., T.L. and A.R. recorded songs on

47 the field. A.R. measured acoustic variables and interference scores. A.R. performed analyses. A.R. wrote

48 the first draft. All authors contributed to revisions of the manuscript, approved its final version and

49 accept to be held accountable for its content.

50 
51 Patterns of bird song evolution on islands support the character release hypothesis in tropical but

52 not in temperate latitudes

53 Abstract

54 The character release hypothesis - which predicts that a decline in interspecific competition leads to

55 the expansion of trait expression - remains to be tested for communication signals. Taking advantage of

56 the fact that oceanic islands host fewer species than the mainland, we tested whether island birds show

57 an increase in frequency bandwidth of acoustic signals compared to mainland birds. Given the higher

58 animal diversity and more saturated acoustic space in the tropics, we expected acoustic character release,

59 if any, to be stronger in the tropics than in the temperate zone. We field recorded 22 bird species (11

60 pairs consisting of an endemic island species and its closest mainland relative) breeding at similar

61 latitudes and in similar habitats: 6 tropical pairs (São Tomé Island / Mount Cameroon), and 5 temperate

62 pairs (Madeira Island / southern France). For each species, we measured the degree of acoustic

63 interference experienced when vocalizing, and the spectral characteristics of its song (minimum and

64 maximum frequencies, bandwidth). As expected, island species spent more time vocalizing alone, and

65 any overlap in vocalizations involved fewer species. The vocalizations of island species spanned broader

66 frequency bandwidths than their mainland counterparts in the tropics (true for all 6 pairs), but this pattern

67 was less evident in the temperate region (2/5 pairs with no marked differences and $1 / 5$ with opposite

68 pattern). Overall, the character release of communication signals only occurred where the differential in

69 number of species was large (tropics). We discuss latitude differences and the potential factors driving

70 the observed differences.

71

72

Keywords: Acoustic communication, Interspecific competition, Sexual signals, Tropics. 


\section{Introduction}

75 Ecological opportunity, defined as the availability of ecologically accessible resources that may be exploited (Stroudt \& Losos 2016), is a crucial driver of trait diversification and radiation (Schluter,

77 2000). It can arise when a species loses one or more close competitors, which allows it to expand its

78 niche into areas previously occupied by the competitor(s), in a process labelled as character release

79 (Grant 1972; Herrmann et al. 2020). Oceanic islands, characterised by species-poor communities with

80 low levels of inter-specific competition (Whittaker et al 2007), offer an ideal setting for the study of

81 character release. Character release has been well documented on islands in relation to diet, with island

82 species being on average more generalist than their mainland counterparts (e.g. Diamond 1970; Lister

83 1976; Cox \& Ricklefs 1977). Animal communication strategies, that are expected to be affected by the

84 level of species interference, could also show signs of character release (Naugler \& Ratcliffe, 1994). In

85 particular, species interference is expected to affect acoustic signals that transmit over long distances and, thus, can easily mask each other (Wilkins, Seddon, \& Safran, 2013). Hence, acoustic signals are

87 good candidates for character release (Wollerman \& Wiley, 2002).

Acoustic signalling is a widespread type of communication for many organisms including insects, frogs, mammals and birds (Catchpole \& Slater 1995; Bradbury \& Verhencamp 2011). Specific acoustic signals may facilitate species recognition, avoid costly interbreeding (Seddon 2005; Kirschel

91 et al. 2009a; Pfennig \& Pfennig 2009), and decrease aggressiveness (Doutrelant et al. 2000; Seehausen

$92 \&$ Schluter 2004). Acoustic signals have two physical dimensions: one corresponding to the energy

93 distribution in the temporal domain (how the signal changes over time), and the other to the frequency

94 domain (how much of the signal lies within each given frequency band over a range of frequencies).

95 The frequency domain is likely an appropriate target for character release when competition is reduced.

96 In particular, the frequency bandwidth (the difference between maximal and minimal frequency) is

97 expected to be related to the diversity of singing species in a given community (Wilkins et al. 2013).

98 Indeed, increasing competition for acoustic space is expected to lead to increased partitioning of its use

99 (Slabbekoorn \& Planqué, 2008; Weir et al., 2012; Robert et al., 2019) and, symmetrically through the

100 principle of character release, a decrease in interspecific acoustic competition is expected to allow each 
101 species to expand its bandwidth into spectral areas previously occupied by others (Weir et al., 2012).

102 Yet, few studies have been conducted because opportunities to test this hypothesis are scarce.

Oceanic islands provide an ideal setting to determine to which extent character release affects acoustic signals. Small, isolated oceanic islands present simplified biotas regarding the mainland, with less species and lower competition (Whittaker et al. 2017). The reduced species richness on islands translates in fewer vocalizing species, resulting in less saturated soundscapes (Robert et al. 2019). Hence, acoustic interference is also expected to decrease on islands. Acoustic interference mask signal frequencies, reducing signal perception and discrimination (Lohr et al. 2003). Even if species are able to improve their capacity to extract important information in noisy environments (Aubin \& Jouventin 1998; Lengagne et al. 1999; Benney \& Braaten 2000), their signals are also expected to minimize interference and rapidly change when constraints are increased or relaxed (Luther \& Gentry 2013; Derryberry et al. 2020). While some song traits, such as syllable diversity, are probably unaffected by the selective pressure to avoid interference, it has been shown that song frequency range was inversely related to the complexity of the acoustic environment (Naugler \& Ratcliffe 1994, Grant \& Grant 2010,

115 Weir et al. 2012). To date, the large majority of work comparing bird song on islands versus mainland has focused

117 on the temporal domain, i.e. syntax or note composition (reviewed in Price 2008; Parker et al. 2012; Lachlan et al. 2013; Potvin \& Clegg 2014). For frequency bandwidth, one study testing the character release hypothesis found that species with fewer same-family sympatric species used wider frequency bandwidths, and detected a non-significant trend of insularity on this trait (Morinay et al. 2013). One possible reason for this non-significant result is that the authors used songs from public libraries that were recorded in different habitats and conditions and with different material. This uncontrolled variation in song recordings may have masked island-mainland differences. Only a carefully designed field-based study can control these variations and thus test whether frequency bandwidth is different on islands compared to the mainland.

To determine whether changes occur in the frequency bandwidth of island birds, we conducted

127 controlled recordings in the field (in similar habitats and using the same recording equipment) of bird 128 species vocalizing on two oceanic islands and their closest relatives on the mainland. We obtained sound 
recordings for 11 pairs of bird species belonging to four communities situated in a tropical zone rainforests of São Tomé Island and Mount Cameroon - and in a temperate zone - laurel forests of Madeira Island and evergreen oak forests of Southern France. These four communities have been previously studied and sound propagation experiments showed similar environmental filtering for each island/mainland habitat pair (Robert et al., 2019). The four communities presented a gradient of acoustic constraints linked to the diversity of bird and insect species, with both mainland communities containing more vocalizing species than island communities (Robert et al., 2019). On Madeira Island, 13 species breed in the habitat we sampled (Romano et al. 2010), whereas c. 50 species breed in the temperate mainland habitat (Dubois Le Maréchal et al 2008). On São Tomé Island, 25 land bird species are forest breeding residents (Jones \& Tye 2006) in contrast to the c. 350 species breeding on Mount Cameroon (Njabo 2015). A previous study comparing island and mainland soundscapes showed that higher species richness of the mainland communities translated in a more saturated acoustic space, especially in the species-rich tropics (Robert et al., 2019).

First, to evaluate the level of acoustic interference that each focal species has to cope with, and thus the potential role for interspecific interactions in the observed frequency bandwidth on islands, we compared the proportion of time each focal species vocalized alone (without temporal overlap) and the number of species co-vocalizing with each song of the focal species in relation to latitude and insularity. We expected the proportion of time each focal species vocalized alone to be lower on the mainland than on the islands and, hence, a higher degree of acoustic interference among species in the mainland communities. Secondly, we tested if species living in habitats with less acoustic interference (islands) exhibited vocalizations with broader frequency bandwidths than their mainland counterparts. Such a difference would support the hypothesis of character release for island birds compared to the mainland community from which they originated. Because acoustic interference among species is potentially higher in the species-rich tropics, we further expected character release to be more prevalent on the tropics than on the temperate island, as the difference in species richness between islands and mainland is smaller in the latter. Thirdly, we determined whether differences in frequency bandwidths were triggered by a change in lower and/or higher frequencies of bird vocalizations. Inside the frequency range limited by hearing capacity (Dooling 1982; Okanoya \& Dooling 1988), the upper limit of the 
157 frequency bandwidth of bird vocalization is mostly determined by extrinsic factors, such as insect noise

158 (Kirschel et al. 2009b) and environmental filtering (Marten \& Marler 1977), whereas the lower limit of vocalization frequencies is mostly constrained by intrinsic factors linked to the vocal cord length (Ryan \& Brenowitz 1985). Hence, we predicted that differences between mainland and island birds should occur more in high than low frequencies, when controlling for body size (as a proxy of vocal cord length).

\section{Material and methods}

\section{Species pairs and study area}

We worked on two pairs of island and mainland acoustic communities. The tropical pair comprised São Tomé Island, hereafter referred to as tropical island, and Mount Cameroon, hereafter referred to as tropical mainland. The temperate pair comprised Madeira Island, hereafter referred to as temperate island, and southern France, hereafter referred to as temperate mainland. São Tomé $\left(859 \mathrm{~km}^{2}\right)$ and Madeira $\left(801 \mathrm{~km}^{2}\right)$ are two oceanic islands that were never connected to the mainland from which they are separated by c. $250 \mathrm{~km}$ and $657 \mathrm{~km}$, respectively. We worked on comparable mature laurel and evergreen oak forests in the temperate zone, and on primary rainforests in the tropics. For each of the four communities (tropical island, tropical mainland, temperate island and temperate mainland), we worked at three sites (separated by at least $3 \mathrm{~km}$, Appendix 1 in Supporting Information).

On islands, we recorded the common vocalizing species. We then recorded their closest vocalizing relatives on the mainland in order to test the hypothesis that bird song is a trait affected by character release after colonisation of islands (see Appendix 2 in Supporting Information). In the tropics, AR, TL, MM \& CD recorded the vocalizations of six species pairs, including two non-oscines (pigeons and cuckoos) and four oscines. On the temperate mainland, AR, SJ and CD recorded the vocalizations of five pairs of oscines species. The pairs were chosen in order to maximize evolutionary relatedness (as we aimed to investigate how species songs diverge on islands relatively to the song of their mainland counterparts) based on molecular phylogenies or on current taxonomy (as in Covas 2012; Morinay et al. 2013, Doutrelant et al. 2016). Although the sunbird pair is made up of two species currently placed in two distinct genera, ongoing molecular analyses have recovered them as sister species (Rauri Bowie, 
Martim Melo \& Luis Valente, unpublished data). If several mainland species were good candidates (it

was the case for 1 out of the 11 pairs, the flycatcher pair), we chose the one living in the same habitat. All 11 island taxa have been described as either a different species or a differentiated subspecies from mainland populations, except for the robin which was formerly described as an endemic subspecies in Macaronesia (Hounsome 1993) but is now classified within the nominate Erithacus $r$. rubecula (Clements 2000; Garcia del Rey 2011; del Hoyo et al. 2019). Except for the cuckoo pair, all tropical pairs are made of well differentiated species. By contrast, in the temperate region all pairs represent conspecific populations or a very recent speciation event in the case of the firecrests (whose island population was treated as conspecific with the mainland species until recently, Päckert et al. 2001). Hence tropical pairs are derived from older divergence events (most having occurred in the PlioPleistocene border, c. 2-3 mya: Melo 2007) than temperate pairs.

\section{Morphological data}

We obtained the body mass for each of the 22 focal taxa. We found body mass data in the literature for tropical mainland and all temperate taxa (Regulus madeirensis: Del Hoyo et al. 2019; Madeiran robin and blackbird: Hounsome 1993; Madeiran chaffinch: Grant 1979; Madeiran blackcap: Dietzen et al. 2008). For São Tomé island taxa, body mass data were collected on the field by MM (available on SAFRING database, University of Cape Town). When only ranges were reported or when masses were reported separately for males and females, we assumed the midpoint median was the mean of the two values. Body mass did not differ significantly between island and mainland species (pairwise comparisons using Wilcoxon rank-sum test, $\mathrm{P}>0.35)$.

\section{Recordings and acoustic data}

Sites, recording apparatus and audio materials used here were the same as in Robert et al. (2019). Robert et al. (2019) analysed soundscape organization at the community level, whereas here we focus on 11 island-mainland species pairs and analyse a distinct set of acoustic variables (related to expected

211 responses to a relaxation of acoustic interference). Acoustic data were collected during the breeding 212 season (temperate mainland: Apr 2017; temperate island: Mar 2017; tropical mainland: Nov 2016; 
tropical island: Sept 2016). Dates of fieldwork differ among the four communities but are equivalent in terms of timing of the breeding season (Christy \& Clarke 1998; Jones \& Tye 2006; Garcia del Rey, 2011; Serle 1981; Vokurková et al. 2018; del Hoyo et al. 2019). The recording apparatus consisted of four unidirectional microphones ME66/K6 [Sennheiser, Hanover] (flat frequency response between $40 \mathrm{~Hz}$ and $20 \mathrm{kHz}$ ) coupled with a FR2 recorder [Fostex, Tokyo], and three Song Meter SM3 recorders [Wildlife Acoustics, Maynard] equipped with omnidirectional microphones. The sampling frequency was $44.1 \mathrm{~Hz}$ and 16-bit recordings were saved in .wav format on 32GB SDHC cards.

\section{Omnidirectional recordings and species temporal interference}

In each of the three sites of each of the four communities, we sampled dawn choruses with omnidirectional Song Meters. Dawn chorus concentrates the strongest vocal activity for most bird species (Dabelsteen \& Mathevon 2002; Henwood \& Fabrick 1979) and thus corresponds to the strongest acoustic competition period. Each morning, the three microphones were set at least $200 \mathrm{~m}$ apart to ensure acoustic independency (Hart et al 2015). They were positioned on trees at $2 \mathrm{~m}$ height and configured to record continuously for $2 \mathrm{~h} 30$ ( $1 \mathrm{~h}$ before sunrise, $1 \mathrm{~h} 30$ after sunrise). Each studied community was recorded for nine days, three days at each site. Each day, we realized three simultaneous passive recordings (with our three Song Meters), resulting in a total of 27 recordings of dawn chorus per studied community. We then analysed the eight highest-quality omnidirectional recordings (e.g., those without rain or human disturbance); if more than eight high-quality recordings were available, eight were selected at random from all high-quality recordings. These recordings represented at least six different days and each of the three distinct sites for each community.

For each recording, we analysed ten periods of three minutes each. These 10 three-minute periods were taken at the beginning of each quarter of an hour for the $2 \mathrm{~h} 30$ period of recording. Overall, we analysed 30 minutes for each song meter record and 240 minutes for each community (we analysed eight recordings per community). Focusing on the 22 species we studied, and in order to assess temporal interference, we determined the start and end times of each identified vocalization during the threeminute periods of each recording by using cursor placement in Avisoft-SASLAB Pro software. We defined a silence as any period of time without vocalization for more than $1 \mathrm{~s}$. We identified each species 
of vocalizing bird, but we were unable to do the same for insects whose vocalizations were classified

242 into distinct 'types'. To assess the extent to which other vocal bird species and insects interfere temporally with the vocalization of each focal species, we measured two proxies for each of them: i) the

244 proportion of time the species vocalized alone (without any other bird species or type of insect calls temporally overlapping) during the 10 three-minute periods and ii) the number of other species covocalizing with each vocalization produced by the focal species during these 10 three-minute periods.

\section{Unidirectional recordings and frequency bandwidth}

249 To investigate changes in vocalization frequency within species pairs, we performed unidirectional recordings of the vocalizations of the focal species in the three sites of each of the four communities described above. For the two non-oscines pairs (pigeon and cuckoo), we recorded vocalizations recognized as "song" by the ornithologist community, based on our own experience, and on Xeno-canto (www.xeno-canto.org) and Macaulay (Cornell Lab of Ornithology, http://macaulaylibrary.org) online libraries. Observers always stood at least $200 \mathrm{~m}$ apart to ensure that vocalizations would be acoustically independent and would come from distinct individuals. Frequency parameters are only accurate if they are calculated from recordings obtained at short distances (high frequencies fade with distance) and against a low background noise. For this reason, even if we often recorded more than 25 individuals per species, we restricted signal analysis to the highest quality recordings performed at a distance lower than $30 \mathrm{~m}$, mostly between 5 and $20 \mathrm{~m}$ from the recorded bird. Overall, we analysed on average $8.75 \pm 1.77$ (mean \pm se) individuals per species (1352 songs and 194 individuals analysed in total, $8.82 \pm 1.84$ songs per individuals, and $61.5 \pm 34.04$ songs per species; see Appendix 3 in Supporting Information for sample sizes per species and raw data). We did not use songs from online libraries because they were obtained with a variety of recording methods and sourced from different habitats, factors that can affect song frequency (Smith et al 2013).

Using high resolution power spectra and amplitude thresholds, we determined the minimum frequency and the maximum frequency for each song (Zollinger et al 2012) with Avisoft-SASLAB Pro

267 software [Avisoft Bioacoustics, Berlin] (Appendix 4 in Supporting Information). Amplitude thresholds 
were always included between 13 and $18 \mathrm{~dB}$ below the song peak amplitude (amplitude of the loudest

269 frequency). We checked the correctness of measurements visually on spectrograms (Appendix 4 in

270 Supporting Information; FFT, 1024; Frame, 50\%; Window, Hamming; Overlap, 50\%). We then

271 computed frequency bandwidth as the $\log$ (maximum frequency)- $\log$ (minimum frequency) for each

272 song. Using this ratio scale is more biologically meaningful because birds, as other terrestrial

273 vertebrates, perceive frequency on a logarithmic scale (Levitin \& Rogers 2005; Cardoso 2013).

274 Comparison of frequency differences on a linear scale could bias the results by overestimating the

275 importance of the higher-frequency relative to the lower-frequency domain (Cardoso 2013). It was not

276 possible to analyse data blind to location (island/mainland) because, for most of the species pairs, songs

277 differed between island species and their mainland counterparts.

278 We computed accumulation curves for frequency bandwidths of each studied species separately

279 (Appendix 5 in Supporting Information). Accumulation curves allow us to see whether we had recorded

280 enough individuals to characterize species song bandwidths in an accurate way. For all of the focal

281 species, accumulation curves of the average frequency bandwidth against sampling effort reached a

282 plateau indicating that sampling sizes were adequate.

\section{Statistical analyses}

\section{Do species have greater temporal overlap on the mainland?}

287 We assessed whether temporal interference differed between island and mainland by analysing two dependent variables separately: (1) the proportion of time during which a focal species vocalized alone and (2) the number of species co-vocalizing. We used a generalized linear mixed-effects model (GLMM) with $R$ package lme4 (Bates et al. 2015). For both variables, we only retained the three-minute periods during which the focal species was detected. We used a binomial error distribution (species vocalizing alone or not) and a Poisson error distribution (number of species co-vocalizing) for the dependent variables (1) and (2), respectively, and weighted analyses by the total duration each species vocalized. We tested insularity (island/mainland), latitude (tropical/temperate), and their interaction as 295 fixed effects, and conducted pairwise post-hoc analysis. We also included time of the quarter as a 
continuous variable since the vocal activity of birds is expected to decrease as the morning progresses

297 (Dabelsteen \& Mathevon 2002). We included "species" nested in "pair" nested in "family" as random

298 factors to account for taxonomic structure of the data. For each dependent variable, we selected the best model by minimizing the Akaike criterion AIC (Akaike 1987), and considered that models differing by less than 2 AIC units were equivalent. P-values and degree of freedom were approximated with Kenward-Roger approach in pbkrtest package (Halekoh \& Højsgaard 2014).

Does song frequency bandwidth increase on islands?

We assessed how song frequencies differed between islands and the mainland by analysing three dependent variables separately: (i) frequency bandwidth, (ii) minimum frequency, and (iii) maximum frequency. We compared these variables between mainland and island using linear mixed-effects models (LMM, using a Gaussian error distribution) with the lme4 $R$ package (Bates et al. 2015). We included 'individual' nested in 'species' nested in 'pair' nested in 'family' as random factors to account for the phylogenetic structure of the data (Griffith 2000; Beauchamp 2004; Covas 2012; Morinay et al. 2013; Doutrelant et al. 2016). We tested insularity (island/mainland), latitude (tropical/temperate), and their interaction as fixed effects, as these factors are both linked to the level of community complexity. We included bird mass as a proxy for vocal cord length, as this primarily determines the minimum frequency that a bird can achieve (Naugler \& Ratcliffe 1994; Potvin 2013). Best model selection was done as described for temporal overlap. In order to test homogeneity of individual variance in frequency bandwidth between island and mainland species, we performed Bartlett tests. Details of the analyses are presented in the Appendix 6 (Supporting Information). Even if we predicted different patterns of

317 frequencies on islands and mainland, we were also interested in assessing which species in particular could drive these trends. For this, we conducted a comparison of frequency bandwidth at species level, i.e., for each of the 11 mainland-island pairs of species using t-tests. As these repeated tests lead to multiple comparisons risk, we used Benjamini \& Hochberg (1995) method of false discovery rate in order to adjust p-values and control the expected proportion of false discoveries amongst the rejected hypotheses. All statistical analyses were conducted in R v.3.05.1 ( $R$ Development Core Team 2017). 
325 In order to investigate how phylogenetic relationships among species could influence the results, we analysed the same variables (minimum frequency, maximum frequency, frequency bandwidth and

327 number of overlapping species) using a Bayesian phylogenetic mixed model (BPMM) approach. We did not model the proportion of time each species spent vocalizing alone because binomial distributions are not supported by these analyses. Details of the analyses are presented in the Appendix 7 (Supporting Information).

\section{Results}

\section{Species interference}

334 We detected 65 bird species (from 29 families) and 25 different types of insect calls in the tropical mainland, 16 bird species (from 13 families) and 11 different types of insect calls on the tropical island, 21 bird species (from 13 families) in the temperate mainland and 8 bird species (from 6 families) on the temperate island. We detected no insect calls in the recordings of the temperate zone.

The proportion of time that a focal species vocalized alone varied in relation to insularity and latitude: tropical species vocalized less often alone than temperate species, and mainland species vocalized less often alone than island species (Table 1, Fig. 1). Moreover, post-hoc analyses showed that the island-mainland difference was higher in the tropical zone (difference $=-0.17 \pm 0.03$ for the temperate zone and $-1.55 \pm 0.42$ for the tropics, $\mathrm{P}<0.01$ in both cases). As expected, species that vocalized earlier in the morning were less likely to vocalize alone (Table 2).

The number of species co-vocalizing with the focal species is affected by the interaction between insularity and latitude (Table 1, Fig. 2). On the mainland, species vocalizations overlapped with the vocalizations of more species than on islands (Table 1, Fig. 2). The overlap included more species in the tropical than in the temperate zone (Table 1, Fig. 2). Post-hoc analyses showed that the islandmainland difference was greater in the temperate $(P<0.001$ and estimate $=-0.74 \pm 0.02)$ than in the tropical zone $(P<0.001$ and estimate $=-0.47 \pm 0.03)$. Finally, focal species overlapped with more species 350 when vocalizing earlier (during the dawn chorus) than later in the morning (Table 1). Results of BPMM 351 were the same (Appendix 7 in Supporting Information). 


\section{Frequencies}

354 Our analyses of frequency bandwidth variation showed a significant interaction between insularity and latitude (Table 2). Frequency bandwidth was broader on the tropical island than on the tropical mainland, but no significant difference was found in the temperate area (Fig. 3). Bird mass had no significant effect and was not retained in the best model (Table 2 and Appendix 8 in Supporting Information).

Our prediction that maximum frequencies should be higher on islands compared to the mainland held strongly for the tropics but not for the temperate zone (Table 2, Fig. 3 and Appendix 9-10 in Supporting Information). Finally, minimum frequencies were not significantly different on islands (Table 2, Fig. 3 and Appendix 9-10 in Supporting Information). As expected mass was negatively correlated to minimum and maximum frequencies (Table 1).

Results of Bayesian phylogenetic mixed models (BPMM) corrected for phylogenetic relatedness were equivalent in terms of significance and relative strength of estimates (Appendix 7 in Supporting Information). In particular, results of BPMM indicated broader frequency bandwidths on the islands compared to the mainland, and stronger island-mainland differences in the tropics compared to the temperate zone. We found the same significant interaction between latitude and insularity in the variations of maximum frequencies. However, BPMM recovered a significant diminution of minimum frequencies in islands.

When looking at each species independently (t-tests, Fig. 3), we found that in the tropics three of 371 the six species pairs showed broader frequency bandwidths on the island (cuckoos: $P<0.001$, orioles: $372 P<0.001$ and flycatchers: $P<0.001)$. The three other pairs - speirops, sunbirds, and pigeons - showed 373 trends in the same direction but the differences were not significant. In the temperate region, the effect 374 of insularity was only present in the robins and firecrests that had a broader bandwidth on the island $(P=$ 3750.048 and $P<0.001$ respectively). The chaffinches, on the contrary, had a narrower bandwidth on the island $(P<0.001)$. The blackbird and blackcap pairs showed no significant differences in bandwidth 377 between island and mainland.

378 Among the pairs with broader frequency bandwidth on islands, broader bandwidth was achieved 379 by all individuals (individuals with lowest bandwidths on the island population had higher frequency 
bandwidths than individuals with lowest bandwidths in the mainland population) (Appendix 6 in

381 Supporting Information). This was also the case for the flycatcher, the only species that had a significantly different (greater) variance among individuals on the island than the on the mainland (Appendix 6 in Supporting Information).

\section{Discussion}

386 This study showed that, on islands, birds vocalize more often alone and co-vocalize with a lower 387 number of species than on the mainland. As such, island species face less acoustic interference from sympatric species, the necessary condition for the occurrence of character release of acoustic signals. Evidence for character release was detected but, as predicted, it was much more prevalent on the tropical rather than the temperate island: i) the proportion of time each species vocalized alone was greater in the temperate than in the tropical region, and ii) all tropical island birds tended to sing with a broader frequency bandwidth than mainland species, a result only replicated in two of the five temperate species. This broader bandwidth did not reflect higher inter-individual variance among island birds, but was achieved by all individuals in the island population. Broader frequency bandwidths were mostly the result of an increase in maximal frequencies rather than a decrease in minimal frequencies, in accordance with being a response to changes in the environmental soundscape on islands (decrease in acoustic interference).

\section{Character release: the central role of competition}

The association between lower acoustic interference and broader bandwidths of bird songs observed on islands, relatively to the mainland, suggests that the relaxation of interspecific competition may have played a role in the evolution of acoustic signals on islands, as predicted by the character release hypothesis. Community composition is considered as one of the major constraints affecting signal evolution (Wilkins et al. 2013). For instance, many studies recorded frequency partitioning at the community level in insects (Sueur 2002; Shieh et al. 2015), fish (Ruppé et al 2015), (Duellman \& Pyles

406 1983; Sinsch et al. 2012), and birds (Luther 2009; Robert et al. 2019; but see Slabbekoorn \& Planqué 407 2008; Seddon and Tobias 2010, Tobias et al. 2014). 
Character release could be due to a change in two non-exclusive factors. First, interspecific competition between closely related species, using the same song features and frequency windows (Kroodsma 1977; Luther 2009; Weir et al. 2012), is likely to lead to high signal overlap and hence to an increase in communication errors. These misdirected interactions are expected to lead to reproductive

412 or agonistic character displacement (Kirschel et al. 2009a; Grant \& Grant 2010). Secondly, frequency

413 interference from other biotic sources can mask the signal produced and harm its integrity (Lohr et al. 414 2003) and, under the sensory drive hypothesis (Endler 1992), changes in biotic constraints should lead 415 to rapid changes to minimize signal degradation and maximize discrimination (Tobias et al., 2010; 416 Luther \& Gentry 2013). Such changes in signal design should occur when biotic constraints are either 417 increased or relaxed.

418 Here, the importance of the acoustic community saturation on the change in frequency range is supported by two findings. First, the effect of insularity was much stronger in the tropics, in accordance with the much stronger decrease in species richness between island and the mainland. In our study systems, bird species diversity on the tropical island was c. 14 times lower than on the mainland, whereas

422 in the temperate region it was only c. 4 times lower. Secondly, we found that, in the tropics, the frequency bandwidth widened mostly by increasing the maximum frequency, which is more often associated with environmental constraints, including the sounds of insects. Insects are the primary source of noise in tropical rainforest (Luther \& Gentry 2013). Insects have been shown to change the way green hylia (Hylia prasina) vocalizes in Cameroon (Kirschel et al 2009b), and they are invoked as

427 a reason why species breeding in tropical forests vocalize across narrower bandwidths than at high 428 latitudes (Weir et al 2012). Nevertheless, this interference effect does not exclude the effect of reduced competition among closely related species. To disentangle the role of each process, studies controlling for the sound propagation properties of the habitat, such as ours, must be extended to different communities where the number of closely-related sympatric species varies. It will then be possible to assess the relative roles of acoustic competition with close relatives and ambient noise in shaping the evolution of song frequencies.

\section{Character release: less prevalent on temperate islands}


The wider frequency bandwidth of island species is observed for most of the tropical species, but only

437 for two of the temperate species (Erithacus rubecula and Regulus madeirensis). This may be explained

438 by the fact that temperate mainland species already (i) exhibit a very wide frequency bandwidth 439 compared to tropical mainland species (Fig. 3) (Weir et al 2012) ii) spend a larger proportion of time 440 vocalizing alone (Fig. 1), and (iii) co-vocalize with fewer species (in average only one, Fig. 2). Under 441 these conditions, the frequency bandwidth of some temperate mainland species may have already 442 reached its maximum value and may be constrained on islands because of limiting factors such as 443 physical features of habitat or species morphology. Additionally, a greater island-mainland distance 444 (Madeira is located $657 \mathrm{~km}$ away from the mainland while São Tomé is at $250 \mathrm{~km}$ ) is expected to increase the susceptibility of the island to founder effects and decrease the complexity of vocalizations (reviewed in Price 2008). This may explain the narrowing of the frequency range of the song of the chaffinch from Madeira Island (Fringilla coelebs madeirensis), which is associated with the loss of the terminal 'flourish' - the part of the song with the highest frequency (present in some individual songs in the mainland population, see Figure S3 in Appendix 6). Alternatively, or in combination, because this flourish is the intrasexual element of the chaffinch song (Leitão \& Riebel 2003), its loss may have been caused by a release of sexual selection in the island population.

\section{Can other factors affect song observed spectral characteristics?}

454 Predation, sexual selection, territoriality, and sociality are four factors expected to be relaxed on islands (Stamps \& Buechner 1985; Griffith 2000; Beauchamp 2004). Could any of these factors concur to explain the differences we observed here? Predation is known to affect call frequency bandwidth, which can be widened to facilitate heterospecific communication in mobbing for nestling predators and narrowed down to be less detectable (Marler 1955; Dutour et al. 2017). Predation has been shown to lead to evolution of low-amplitude songs (Searcy \& Nowicki 2006), changes in signalling locations (Møller et al. 2008) or in signalling rates (Schmidt \& Belinsky 2013; Akçay et al. 2016), but never to date to changes in song frequency bandwidth. Hence, at this stage inferring a role of predation in the observed differences would be too speculative. A relaxation of sexual selection or territoriality is predicted to decrease song complexity (Kaluthota et al.2016), which can lead to a reduction in frequency 
bandwidth - and may explain what we observed for the chaffinch pair (Fringilla coelebs) as discussed above. Population density is known to increase on islands (MacArthur et al 1972), leading to increased sociality (Stamps \& Buechner 1985). Increased sociality could result in an increased need for individual recognition (Chaine et al. 2018) and thus in higher signal variability (Dale et al. 2001). This mechanism would result in increased frequency bandwidth at the island population level, but not to wider frequency bandwidths at the individual level as we also documented here.

Habitat structure is often presented as one of the most important selective forces for acoustic signal evolution. The Acoustic Adaptation Hypothesis predicts that acoustic signals should evolve towards minimizing the attenuation and degradation of the signal in relation to the structure of each habitat (Morton 1975). Yet, disentangling the role of environmental filtering from the role of acoustic interference can be challenging. For example, Morton (1975) compared the frequency bandwidth of 85 Neotropical bird species and found that species from lower elevations, i.e., living in closed habitats but also in species-rich communities - had significantly narrower song frequency bandwidths than species from higher elevations living in open habitats - but also in species-poor communities. Hence, the observed changes in frequency bandwidth equally fitted predictions arising from differential sound transmission properties in open/close habitats and predictions made for species-poor/species-rich communities. In our study, we controlled for sound propagation properties by recording songs in habitats presenting a similar profile of sound degradation (Robert et al. 2019); therefore, the changes we observe in frequency bandwidths cannot be attributed to habitat differences.

Finally, divergence in frequency bandwidth is often a by-product of morphological divergence (Podos 2001; Krishnan \& Tamma 2016). For instance, wider frequency bandwidths are often found at higher-pitched peak frequencies which have been shown to be associated with lighter body mass (Ryan \& Brenowitz 1985), and wide frequency ranges are more easily produced by shorter bills (Palacios \& Tubaro 2000; Podos et al. 2004). In our models, we controlled for body size and found a significant and expected link between minimum, maximum frequencies and mass but not between bandwidth and mass. Therefore, the documented increase in frequency bandwidth on islands is unlikely driven by differences in body mass. For bill length, island birds - at least in passerines - have usually longer bills (Grant 1968; 
Clegg \& Owens 2002), and thus should have lower-pitched dominant frequencies (Palacios \& Tubaro

492 2000), but no consequences on bandwidth are predicted.

\section{Conclusion}

\section{References}

513 Akaike, H. (1987). Factor analysis and AIC. Psychometrika, 52, 317-332. doi:10.1007/BF02294359.

514 Akçay, Ç, Clay, A., Campbell, S. E., \& Beecher, M. D. (2016). The sparrow and the hawk: Aggressive

Our results showed that 1) island species face more acoustic interference than their mainland closest relatives, and that 2) in the tropics, island birds had a wider frequency bandwidth than their mainland closest relatives. Understanding the reasons of these changes is important to understand processes of species diversification given the central role of signals in pre-mating isolation in birds. Here, we propose that the increase of frequency bandwidth in the song of tropical island birds could be caused by character release after mainland species colonize islands where acoustic space is less satuated. The importance of competition for acoustic space in driving song evolution was underscored by the fact that the widening of the frequency bandwidth of island birds songs was mostly limited to the tropics, where the reduction of interspecific competition and overall acoustic interference upon island colonisation is much more extreme than in the temperate region. This suggests that the impact of the "island environment" on convergent evolution (the "island syndrome": Baeckens \& Van Damme, 2020) can be idiosyncratic, as island traits can vary with latitude, with some being more marked in the tropics (e.g., competition differential as shown here) and others in the temperate region (e.g., environmental stability differential: Covas 2012).

\footnotetext{
signaling under risk of predation. Behavioral Ecology, 27, 601-607. doi:10.1093/beheco/arv196.
}

Aubin, T., \& Jouventin, P. (1998). Cocktail party effect in king penguin colonies. Proceedings of the Royal Society of London, Series B, 265, 1665-1673. doi:10.1098/rspb.1998.0486. 
Bates, D., Mächler, M., Bolker, B. M., \& Walker, S. C. (2015). Fitting linear mixed-effects models using lme4. Journal of Statistical Software, 67(1), doi:10.18637/jss.v067.i01

Baeckens, S., \& R. Van Damme. (2020). The island syndrome. Current Biology 30: 338- 339. doi: 10.1016/j.cub.2020.03.029.

Beauchamp, G. (2004). Reduced flocking by birds on islands with relaxed predation. Proceedings of the Royal Society of London, Series B, 271, 1039-1042. doi:10.1098/rspb.2004.2703.

Benjamini, Y., \& Hochberg, Y. (1995). Controlling the false discovery rate: a practical and powerful approach to multiple testing. Journal of the Royal Statistical Society Series B, 57, 289-300. doi:10.1111/j.2517-6161.1995.tb02031.x

Cardoso, G. C. (2013). Using frequency ratios to study vocal communication. Animal Behaviour, 85, 1529-1532. doi:10.1016/j.anbehav.2013.03.044.

Chaine, A. S., Shizuka, D., Block, T.A., Zhang, L., \& Lyon, B. E. (2018). Manipulating badges of status only fools strangers. Ecology Letters, 21, 1477-1485. doi:10.1111/ele.13128.

Christy, P., \& Clarke, W. V. (1998). Guide des oiseaux de São Tomé et Príncipe. ECOFAC.

Clegg, S. M., \& Owens, I. P. F. (2002). The 'island rule' in birds : medium body size and its ecological explanation. Proceedings of the Royal Society of London, Series B, 269, 1359-1365. doi:10.1098/rspb.2002.2024.

Clements, J. F., T. S. Schulenberg, M. J. Iliff, S. M. Billerman, T. A. Fredericks, B. L. Sullivan, \& C. L. Wood (2019). The eBird/Clements Checklist of Birds of the World: v2019.

Covas, R. (2012). Evolution of reproductive life histories in island birds worldwide. Proceedings of the Royal Society of London, Series B, 279, 1531-1537. doi:10.1098/rspb.2011.1785.

Cox, G. W., \& Ricklefs R. E. (1977). Species diversity and ecological release in Caribbean land bird faunas. Oikos, 28, 113-122. doi: 10.2307/3543330

Dabelsteen, T. \& Mathevon, N. (2002). Why do songbirds sing intensively at dawn? A test of the acoustic transmission hypothesis. Acta Ethologica, 4, 65-72. doi:10.1007/s10211-001-0056-8.

Dale, J., Lank, D. B., \& Reeve, H. K. (2001). Signaling individual identity versus quality: a model and case studies with ruffs, queleas, and house finches. The American Naturalist, 158, 75-86. doi:10.1086/320861. 
Billerman, S. M., Keeney, B. K., Rodewald, P. G., \& Schulenberg, T. S. (Editors) (2020). Birds of the World. Cornell Laboratory of Ornithology, Ithaca, NY, USA.

Derryberry, E. P., Phillips, J. N., Derryberry, G. E., Blum, M. J., Luther, D. (2020). Singing in a silent spring: birds respond to a half-century soundscape reversion during the COVID-19 shutdown. Science, 370, 575-579. doi:10.1126/science.abd5777

Diamond, J.M. (1970). Ecological consequences of island colonization by southwest Pacific birds, I. Types of niche shifts. Proceedings of the National Academy of Sciences USA, 67, 529-536. doi: 10.1073/pnas.67.2.529

Dooling, R. J. (1982). Ontogeny of song recognition in birds. Integrative and Comparative Biology, 22, 571-580. doi:10.1093/icb/22.3.571.

Doutrelant, C., Leitão, A., Otter, K., \& Lambrechts, M. M. (2000). Effect of blue tit song syntax on great tit territorial responsiveness - an experimental test of the character shift hypothesis. Behavioral Ecology and Sociobiology, 48, 119-124. doi:10.1007/s002650000220.

Doutrelant, C., Paquet, M., Renoult, J.P., Grégoire, A., Crochet, P.-A., \& Covas, R. (2016). Worldwide patterns of bird colouration on islands. Ecology Letters, 19, 537-545. doi:10.1111/ele.12588.

Duellman, W. E. \& Pyles, R. A. (1983). Acoustic resource partitioning in anuran communities. Copeia, 1983, 639-649. doi:10.2307/1444328.

Dubois, P. J., Le Maréchal, P., Olioso, G., \& Yésou, P. (2008). Nouvel inventaire des oiseaux de France. Nathan.

Dutour, M., Léna, J.-P., \& Lengagne, T. (2017). Mobbing calls: a signal transcending species boundaries. Animal Behaviour, 131, 3-11. doi:10.1016/j.anbehav.2017.07.004.

Endler, J. A. (1992). Signals, signal conditions and the direction of evolution. The American Naturalist, 139, S125-S153. doi:10.1086/285308.

Garcia-del-Rey, E. (2011). List of the birds of Macaronesia. In: Garcia-del-Rey, E. (Ed.), Field guide to the birds of Macaronesia: Azores, Madeira, Canary Islands, Cape Verde (pp. 314-326). Lynx Edicions.

Grant, B. R., \& Grant, P. R. (2010). Songs of Darwin's finches diverge when a new species enters the community. Proceedings of the National Academy of Sciences USA, 107, 20156-20163. 
doi:10.1073/pnas.1015115107.

575 Grant, P. R. (1972). Convergent and divergent character displacement. Biological Journal of the Linnean Society, 4, 39-68. doi:10.1111/j.1095-8312.1972.tb00690.x.

577 Grant, P. R. (1998). Patterns on islands and microevolution. In: Grant, P. R. (Ed.) Evolution on islands. $578 \quad$ Oxford University Press.

579 Grant, P. R. (1968) Bill size, body size, and the ecological adaptations of bird species to competitive $580 \quad$ situations on islands. Systematic Zoology, 17, 319. doi:10.1093/sysbio/17.3.319

581 Grant, P. R. (1979). Evolution of the chaffinch, Fringilla coelebs, on the Atlantic Islands. Biological Journal of the Linnean Society, 11, 301-332.

583

584

585

586

587

588

589

590

591

592

Griffith, S. C. (2000). High fidelity on islands: A comparative study of extrapair paternity in passerine birds. Behavioral Ecology, 11, 265-273. doi:10.1093/beheco/11.3.265.

Halekoh, U., \& Højsgaard, S. (2014). “A Kenward-Roger approximation and parametric bootstrap methods for tests in linear mixed models - the R package pbkrtest." Journal of Statistical Software, 59, 1-30. doi: 10.18637/jss.v059.i09

Hart, P. J., Hall, R., Ray, W., Beck, A., \& Zook, J. (2015). Cicadas impact bird communication in a noisy tropical rainforest. Behavioral Ecology, 26, 839-842. doi:10.1093/beheco/arv018.

Henwood, K., \& Fabrick, A. (1979). A quantitative analysis of the dawn chorus: temporal selection for communicatory optimization. The American Naturalist, 114, 260-274. doi:10.1086/283473.

Herrmann, N. C., Stroud, J. T, \& Losos, J. B. (2020). The Evolution of 'Ecological Release' into the 21st Century. Trends in Ecology \& Evolution, 36, 206-215. doi: 10.1016/j.tree.2020.10.019.

Hounsome, M. V. (1993). Biometrics and origins of some Atlantic Islands birds. Boletim do Museu Municipal do Funchal, Sup. n², 107-129.

Kaluthota, C., Brinkman, B. E., dos Santos, E. B., \& Rendall, D. (2016). Transcontinental latitudinal variation in song performance and complexity in house Wrens (Troglodytes aedon). Proceedings of the Royal Society of London, Series B, 283, 20152765. doi:10.1098/rspb.2015.2765.

Kirschel, A. N. G., Blumstein, D. T., Cohen, R. E., Buermann, W., Smith, T. B., \& Slabbekoorn, H. (2009). Birdsong tuned to the environment: green hylia song varies with elevation, tree cover, and noise. Behavioral Ecology, 20, 1089-1095. doi:10.1093/beheco/arp101. 
Kirschel, A. N. G., Blumstein, D. T., \& Smith, T. B. (2009). Character displacement of song and morphology in African tinkerbirds. Proceedings of the National Academy of Sciences USA, 106, 8256-8261. doi:10.1073/pnas.0810124106.

Krishnan, A., \& Tamma, K. (2016). Divergent morphological and acoustic traits in sympatric communities of Asian barbets. Royal Society Open Science, 3, 160117. doi:10.1098/rsos.160117.

Kroodsma, D. E. (1977). Correlates of song organization north american wrens. The American Naturalist, 111, 995-1008. doi:10.1086/283228.

Lachlan, R. F., Verzijden, M. N., Bernard, C. S, Jonker, P.-P., Koese, B., Jaarsma, S., Spoor, W., Slater, P., \& Ten Cate, C. (2013). The progressive loss of syntactical structure in bird song along an island colonization chain. Current Biology, 23, 1896-1901. doi:10.1016/j.cub.2013.07.057.

Leitão, A., \& Riebel, K. (2003). Are good ornaments bad armaments? Male chaffinch perception of songs with varying flourish length. Animal Behaviour, 66, 161-167. doi:10.1006/anbe.2003.2167.

Lengagne, T., Jouventin, P., \& Aubin, T. (1999). Finding one's mate in a king penguin colony: Efficiency of acoustic communication. Behaviour, 136, 833-846. doi:10.1163/156853999501595.

Levitin, D. J., \& Rogers, S. E. (2005). Absolute pitch: perception, coding, and controversies. Trends in Cognitive Science, 9, 26-33. doi:10.1016/j.tics.2004.11.007.

Lister, B. C. (1976). The nature of niche expansion in West Indian Anolis Lizards I: ecological consequences of reduced competition. Evolution, 30, 659-676. doi: 10.2307/2407808

Lohr, B., Wright, T. F., \& Dooling, R. J. (2003). Detection and discrimination of natural calls in masking noise by birds: estimating the active space of a signal. Animal Behaviour, 65, 763-777. doi:10.1006/anbe.2003.2093.

Luther, D. (2009). The influence of the acoustic community on songs of birds in a neotropical rain forest. Behavioral Ecology, 20, 864-871. doi:10.1093/beheco/arp074.

Luther, D., \& Gentry K. (2013). Sources of background noise and their influence on vertebrate acoustic communication. Behaviour, 150, 1045-1068. doi:10.1163/1568539X-00003054.

MacArthur, R., Diamond, M. J., \& Karr, R. J. (1972). Density compensation in island faunas. Ecology, 53, 330-3342. doi:10.2307/1934090.

Marler, P. (1955). Characteristics of some animal calls. Nature, 175, 863-864. 
630 Marten, K., \& Marler, P. (1977). Sound transmission and its significance for animal vocalization - I.

631 Temperate habitats. Behavioral Ecology and Sociobiology, 2, 271-290. doi:10.1007/BF00299740.

632 Melo, M., Warren, B. H., \& Jones, P. J. (2011). Rapid parallel evolution of aberrant traits in the 633 diversification of the Gulf of Guinea white-eyes (Aves, Zosteropidae). Molecular Ecology, 20, 49534967. doi:10.1111/j.1365-294X.2011.05099.x.

635 Møller, A. P., Nielsen, J.T., \& Garamzegi, L. Z. (2008). Risk taking by singing males. Behavioral Ecology, 19, 41-53. doi:10.1093/beheco/arm098.

637 Morinay, J., Cardoso, G. C., Doutrelant, C., \& Covas, R. (2013). The evolution of birdsong on islands. Ecology and Evolution, 3, 5127-5140. doi:10.1002/ece3.864.

Morton, E. S. (1975). Ecological sources of selection on avian sounds. The American Naturalist, 109, 17-34. doi:10.1086/282971.

Naugler, C. T., \& Ratcliffe, L. (1994). Character release in bird song: a test of the acoustic competition hypothesis using American Tree Sparrows Spizella arborea. Journal of Avian Biology, 25, 142-148. doi: $10.2307 / 3677033$.

Njabo, K.Y. (2015). The Cameroon Ornithological Club and the important bird area process in Cameroon. Cameroon Ornithological Club Bulletin, 200, 160-168.

Okanoya, K., \& Dooling, R. J. (1988). Hearing in the swamp sparrow, Melospiza georgiana, and the song sparrow, Melospiza melodia. Animal Behaviour, 36, 726-732. doi:10.1016/S00033472(88)80155-6.

Palacios, M. G., \& Tubaro, P. L. (2000). Does beak size affect acoustic frequencies in woodcreepers? Condor, 102, 553-556. doi:10.1650/0010-5422(2000)102.

Parker, K. A., Anderson, M. J., Jenkins, P. F., \& Brunton, D. H. (2012). The effects of translocationinduced isolation and fragmentation on the cultural evolution of bird song. Ecology Letters, 15, 778785. doi:10.1111/j.1461-0248.2012.01797.x. to a common evolutionary problem. The Quarterly Review of Biology, 84, 253-276. doi:10.1086/605079.

657 Podos, J. (2001). Correlated evolution of morphology and vocal signal structure in Darwin' s finches. 
659 Podos, J., Southall, A. J., \& Rossi-Santos, R. M. (2004). Vocal mechanics in Darwin's finches: correlation of beak gape and song frequency. Journal of Experimental Biology, 207, 607-619. doi:10.1242/jeb.00770.

662

Potvin, D. A. (2013). Larger body size on islands affects silvereye Zosterops lateralis song and call frequency. Journal of Avian Biology, 44, 221-225. doi:10.1111/j.1600-048X.2012.05820.x.

Potvin, D. A., \& Clegg, S. M. (2014). The relative roles of cultural drift and acoustic adaptation in shaping syllable repertoires of island bird populations change with time since colonization. Evolution, 69, 368-380. doi:10.1111/evo.12573.

Price, T. D. (2008). Speciation in birds. Roberts \& Company.

Robert, A., Lengagne, T., Melo, M., Gardette, V., Julien, S., Covas, R., Gomez, D., \& Doutrelant, C. (2019). The theory of island biogeography and soundscapes: Species diversity and the organization of acoustic communities. Journal of Biogeography, 46, 1901-1911. doi:10.1111/jbi.13611.

Romano, H., Correia-Fagundes, C., Zino, F., \& Biscoito, M. (2010). Birds of the archipelagos of Madeira and the Selvagens II - New records and checklist update (1995-2010). Boletim do Museu Municipal do Funchal, 60, 5-44.

Ruppé, L., Clément, G., Herrel, A., Ballesta, L., Décamps, T., Kéver, L., \& Parmentier, É. (2015). Environmental constraints drive the partitioning of the soundscape in fishes. Proceedings of the National Academy of Sciences USA, 112, 201424667. doi:10.1073/pnas.1424667112.

Ryan, M. J., \& Brenowitz, E. A. (1985). The role of body size, phylogeny, and ambient noise in the evolution of bird song. The American Naturalist, 126, 87-100. doi:10.1086/284398.

Schmidt, K. A., \& Belinsky, K. L. (2013). Voices in the dark: Predation risk by owls influences dusk singing in a diurnal passerine. Behavioral Ecology and Sociobiology, 67, 1837-1843. doi:10.1007/s00265-013-1593-7.

Searcy, W. A., \& Nowicki, S. (2006). Signal interception and the use of soft song in aggressive interactions. Ethology, 112, 865-872. doi:10.1111/j.1439-0310.2006.01238.x.

Seddon, N. (2005). Ecological adaptation and species recognition drives vocal evolution in neotropical suboscine birds. Evolution, 59, 200-215. doi:10.1111/j.0014-3820.2005.tb00906.x. 
Seddon, N., \& Tobias, J.A. (2010). Character displacement from the receiver's perspective: species and mate-recognition despite convergent signals in suboscine birds. Proceedings of the Royal Society of London, Series B, 277, 2475-2483.doi:10.1098/rspb.2010.0210

Seehausen, O., \& Schluter, D. (2004). Male-male competition and nuptial-colour displacement as a diversifying force in Lake Victoria cichlid fishes. Proceedings of the Royal Society of London, Series B, 271, 1345-1353. doi:10.1098/rspb.2004.2737.

Serle, W. (1981). The breeding season of birds in the lowland rainforest and in the montane forest of West Cameroon. Ibis, 123, 62-74. doi:10.1111/j.1474-919X.1981.tb00173.x.

Shieh, B.-S., Liang, S.-H., \& Chiu, Y-W. (2015). Acoustic and temporal partitioning of cicada assemblages in city and mountain environments. PLoS One, 10, e.0116794. doi:10.1371/journal.pone.0116794.

Sinsch, U., Lümkemann, K., Rosar, K., Schwarz, C., \& Dehling, M. (2012). Acoustic niche partitioning in an anuran community inhabiting an afromontane wetland (Butare, Rwanda). African Zoology, 47, 60-73. doi:10.3377/004.047.0122.

Slabbekoorn, H., \& Planqué, R. (2008). Spectral overlap in songs and temporal avoidance in a peruvian bird assemblage. Ethology, 114, 262-271. doi:10.1111/j.1439-0310.2007.01461.x.

Smith, T. B., Harrigan, R. J., Kirschel, A. N. G., Buermann, W., Saatchi, S., Blumstein, D. T., de Kort, S. R., \& Slabbekoorn, H. (2013). Predicting bird song from space. Evolutionary Applications, 6, 865-874. doi:10.1111/eva.12072.

Stamps, J., \& Buechner, M. (1985). The territorial defense hypothesis and the ecology of insular vertebrates. The Quarterly Review of Biology, 60, 155-181. doi:10.2307/2828392.

Stroud, J. T., \& Losos, J. B. (2016). Ecological opportunity and adaptive radiation. Annual Review of Ecology, Evolution, and Systematics, 47, 507-53. doi: 10.1146/annurev-ecolsys-121415-032254.

Sueur, J. (2002). Cicada acoustic communication: Potential sound partitioning in a multispecies community from Mexico (Hemiptera: Cicadomorpha: Cicadidae). Biological Journal of the Linnean Society, 75, 379-394. doi:10.1046/j.1095-8312.2002.00030.x.

Tobias, J.A., Aben, J., Brumfield, R. T., Derryberry, E. P., Halfwerk, W., Slabbekoorn, H., \& Seddon, N. (2010). Song divergence by sensory drive in Amazonian birds. Evolution, 64, 2820-2839. doi: 
715 Tobias, J. A., Planqué, R., Cram, D. L., \& Seddon, N. (2014). Species interactions and the structure of 716 complex communication networks. Proceedings of the National Academy of Sciences USA, 111, 717 1020-1025. doi:10.1073/pnas.1314337111.

718 Vokurková, J., Motombi, F. N., Ferenc, M., Hořák, D., \& Sedláček, O. (2018). Seasonality of vocal 719 activity of a bird community in an Afrotropical lowland rain forest. Journal of Tropical Ecology, 34, 720 53-64. doi:10.1017/S0266467418000056.

721 Weir, J. T., Wheatcroft, D. J., \& Price, T.D. (2012). The role of ecological constraint in driving the 722 evolution of avian song frequency across a latitudinal gradient. Evolution, 66, 2773-2783. 723 doi:10.1111/j.1558-5646.2012.01635.x.

724 Wilkins, M. R., Seddon, N., \& Safran, R. J. (2013). Evolutionary divergence in acoustic signals: Causes 725 and consequences. Trends in Ecology and Evolution, 28, 156-166. doi:10.1016/j.tree.2012.10.002. 726 Zollinger, S. A., Podos, J., Nemeth, E., Goller, F., \& Brumm, H. (2012). On the relationship between, 727 and measurement of, amplitude and frequency in birdsong. Animal Behaviour, 84, e1-e9. 728 doi:10.1016/j.anbehav.2012.04.026. 


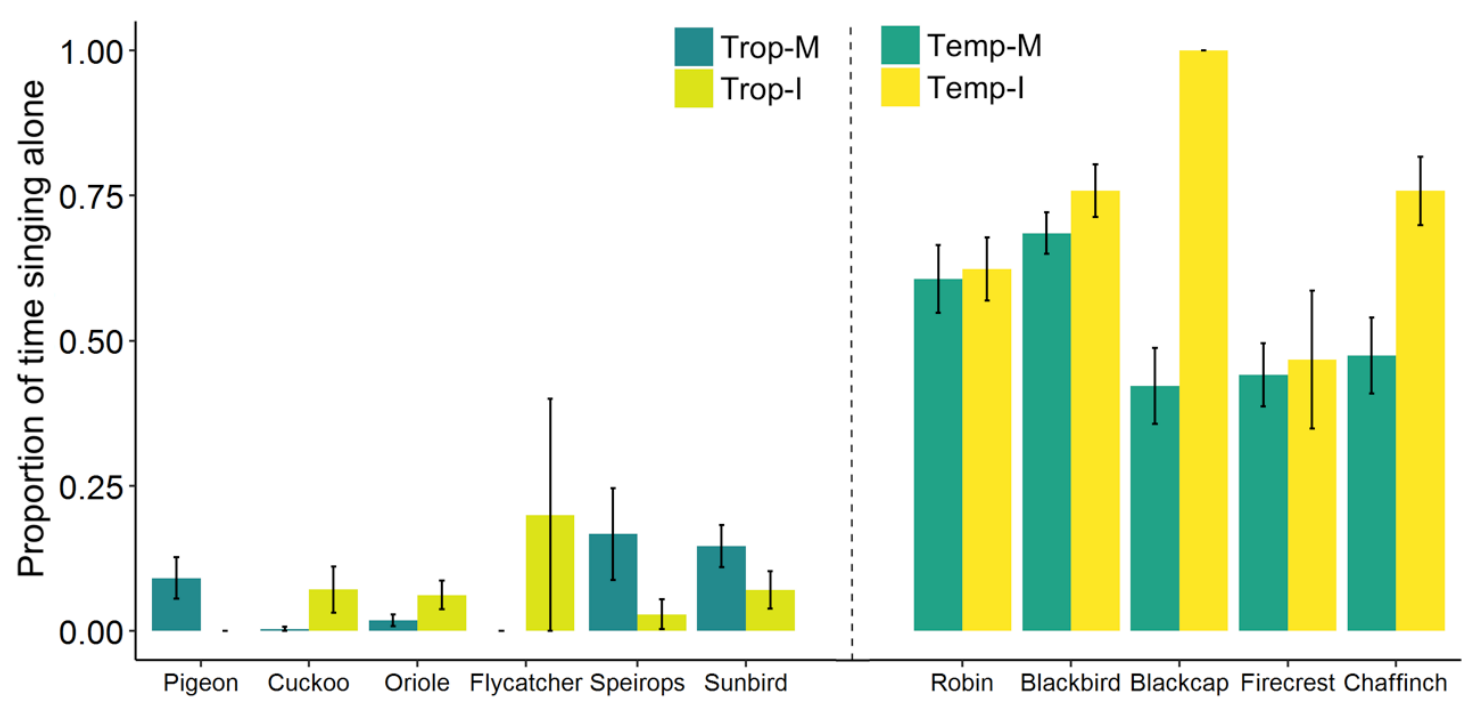

731 Figure 1: Proportion of time (mean \pm standard error of the mean) bird species vocalize alone (without

732 other bird species or type of insect calls). Shown are pairs of closely related species, where one occurs 733 on the mainland (M, green) and the other on an island (I, yellow). Left panel: Tropical (Trop) pairs; 734 Right panel: temperate (Temp) region pairs.

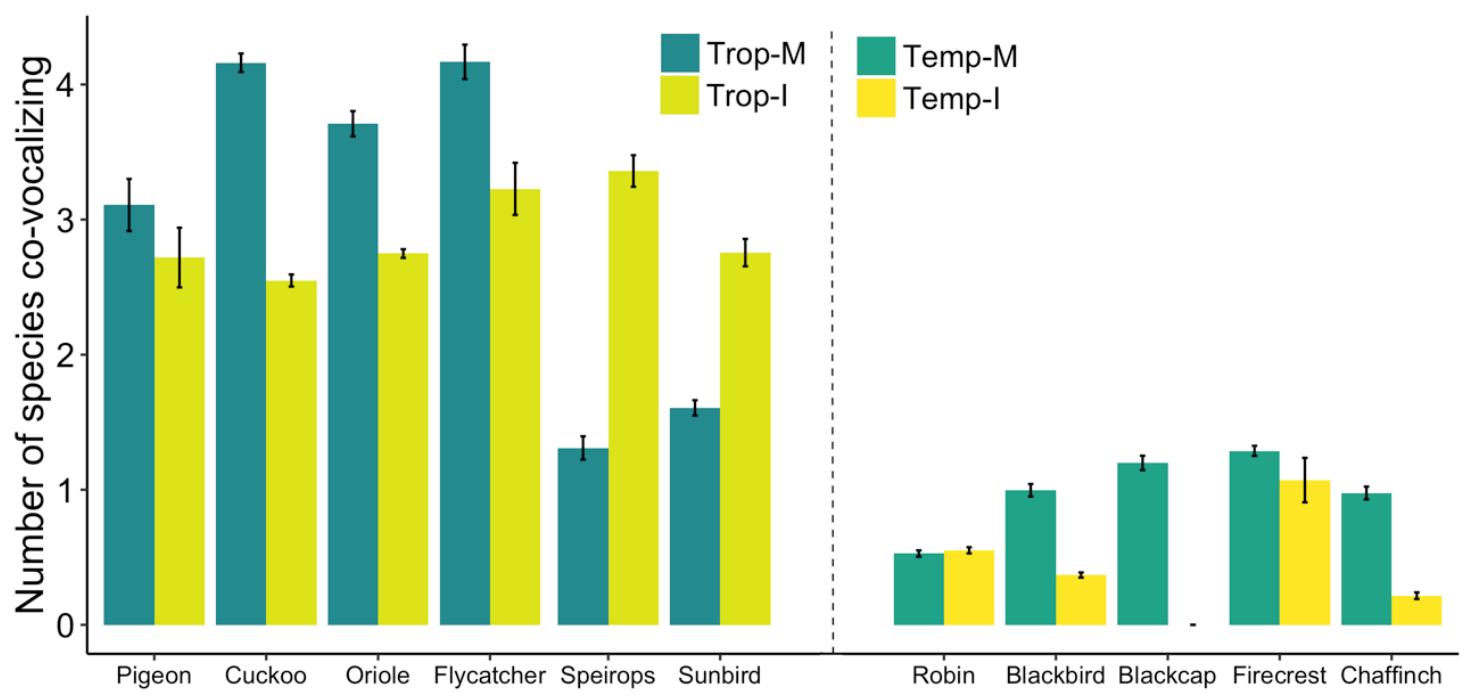

737 Figure 2: Number (mean \pm standard error of the mean) of other bird species and of insect call types covocalizing with each song produced by a focal bird species. Shown are pairs of closely related species, where one occurs on the mainland (M, green) and the other on an island (I, yellow). Left panel: Tropical (Trop) pairs; Right panel: temperate (Temp) region pairs. 


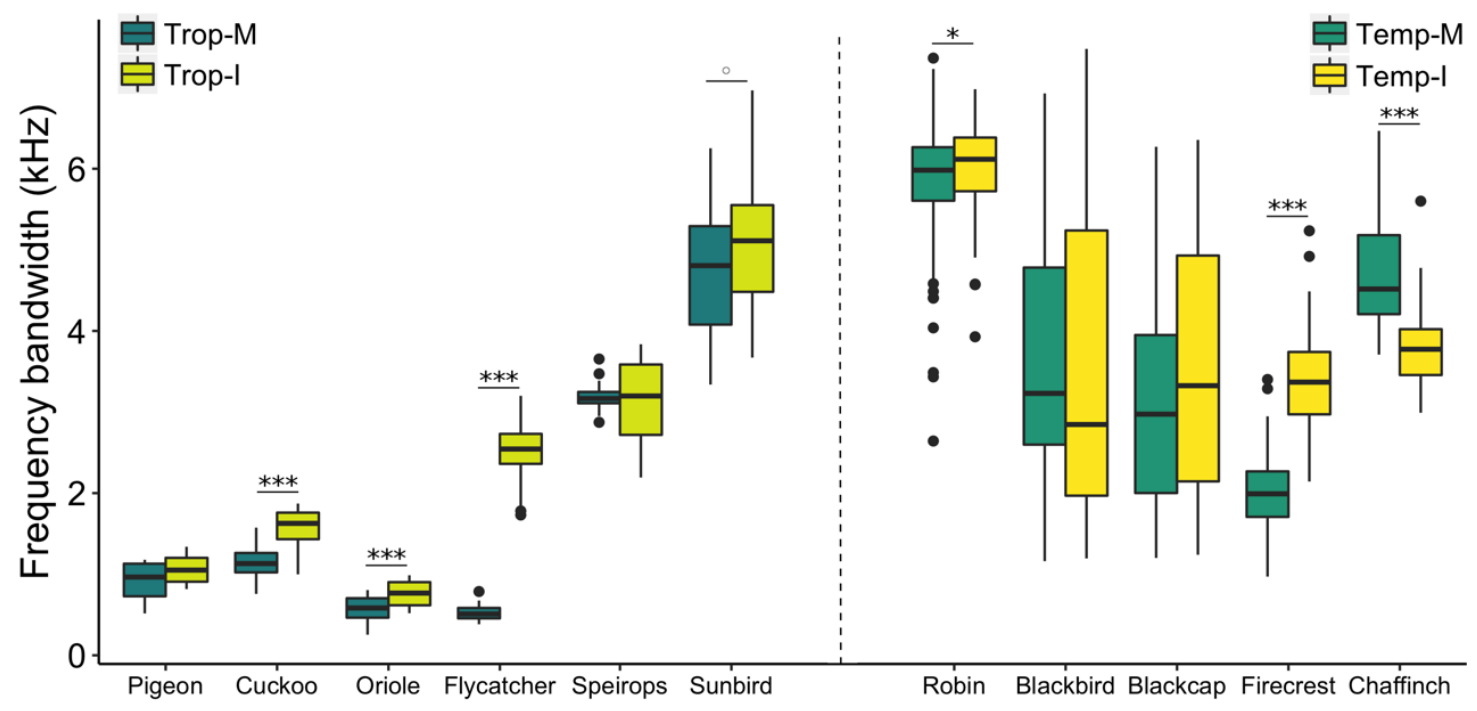

745 Figure 3: Frequency bandwidth of the song of each of the 11 island (I, yellow) bird species and their 746 mainland (M, green) counterparts, in the tropical (left, Trop) and the temperate (right, Temp) regions.

747 Each point is a single song measurement. Symbols associated with p-values for paired t-tests: no symbol:

748 non-significant, ${ }^{\circ}<0.1, *<0.05, * *<0.01 * * *<0.001$. 
749 Table 1: Results of the best models for the two proxies of acoustic interference: proportion of time each

750 focal species is vocalizing alone (GLMM, binomial distribution) and number of species (birds and

751 insects) temporally co-vocalizing with each song of the focal species (GLMM, Poisson distribution)

\begin{tabular}{|c|c|c|c|c|c|c|c|c|}
\hline & \multicolumn{4}{|c|}{ Proportion of time vocalizing alone } & \multicolumn{4}{|c|}{ Number of species co-vocalizing } \\
\hline & $Z$ & df & Estimate & P-value & $Z$ & df & Estimate & P-value \\
\hline Intercept & -0.74 & - & $-0.50 \pm 0.68$ & - & 3.67 & - & $0.44 \pm 0.12$ & - \\
\hline Time after sunrise & 17.21 & 554 & $0.10 \pm 0.006$ & $<0.001$ & -15.81 & 7718 & $-0.03 \pm 0.002$ & $<0.001$ \\
\hline Insularity: "island"1 & 4.85 & 613 & $0.17 \pm 0.04$ & $<0.001$ & -49.61 & 7719 & $-0.74 \pm 0.01$ & $<0.001$ \\
\hline Latitude: "tropic"2 & -4.69 & 16 & $-4.21 \pm 0.90$ & $<0.001$ & 6.02 & 76 & $0.27 \pm 0.03$ & $<0.001$ \\
\hline Insularity*latitude & 3.24 & 52 & $1.38 \pm 0.43$ & $<0.01$ & 8.68 & 7232 & -0.07 & $<0.001$ \\
\hline
\end{tabular}

752 1. Reference category is "mainland"

753 2. Reference category is "temperate"

754

755 Table 2: Results of the best linear-mixed models for the bird song parameters: frequency bandwidth,

756 minimum frequency and maximum frequency. Variables were considered on a logarithmic scale.

\begin{tabular}{|c|c|c|c|c|c|c|c|c|c|c|c|c|}
\hline & \multicolumn{4}{|c|}{ Frequency bandwidth (logged ratio) } & \multicolumn{4}{|c|}{ Minimum frequency (logged) } & \multicolumn{4}{|c|}{ Maximum frequency (logged) } \\
\hline & $T$ & $\mathrm{df}$ & Estimate & $\mathrm{P}$-value & $T$ & $\mathrm{df}$ & Estimate & $\mathrm{P}$-value & $T$ & $\mathrm{df}$ & Estimate & $\mathrm{P}$-value \\
\hline Intercept & 6.10 & - & $0.94 \pm 0.15$ & - & 35.97 & - & $\begin{array}{l}8.05 \pm \\
0.22\end{array}$ & - & 40.43 & - & $\begin{array}{l}8.99 \pm \\
0.22\end{array}$ & - \\
\hline Mass & - & - & - & - & -5.88 & 173 & $\begin{array}{c}-0.007 \pm \\
0.001\end{array}$ & $<0.001$ & -4.75 & 173 & $\begin{array}{c}-0.007 \pm \\
0.001\end{array}$ & $<0.001$ \\
\hline Insularity: "island"1 & -1.06 & 174 & $\begin{array}{c}-0.03 \pm \\
0.03\end{array}$ & 0.29 & -0.90 & 173 & $\begin{array}{c}-0.02 \pm \\
0.02\end{array}$ & 0.37 & -1.56 & 173 & $\begin{array}{c}-0.05 \pm \\
0.03\end{array}$ & 0.12 \\
\hline Latitude: "tropic"2 & -1.33 & 8 & $-0.27 \pm 0.1$ & 0.41 & -1.02 & 8 & $\begin{array}{c}-0.29 \pm \\
0.29\end{array}$ & 0.34 & -1.96 & 8 & $\begin{array}{c}-0.56 \pm \\
0.29\end{array}$ & 0.09 \\
\hline $\begin{array}{l}\text { Insularity*latitude } \\
\text { ("island"1*“tropic"2) }\end{array}$ & 3.28 & 174 & $0.19 \pm 0.06$ & $<0.01$ & -0.91 & 173 & $\begin{array}{c}-0.03 \pm \\
0.04\end{array}$ & 0.36 & 2.78 & 173 & $\begin{array}{r}0.15 \pm \\
0.05\end{array}$ & $<0.01$ \\
\hline
\end{tabular}

757 1. Reference category is "mainland"

758 2. Reference category is "temperate"

759 